\title{
The F-18 High Alpha Research Vehicle: A High-Angle-of-Attack Testbed Aircraft
}

Victoria Regenie, Donald Gatlin, Robert Kempel, and Neil Matheny

(NASA-TM-104253) THE F-18 HIGH

ALPHA RESEARCH VEHICLE: A

HIGH-ANGLE-OF-ATTACK TESTBED

AIRCRAFT (NASA) $17 \mathrm{p}$
N92-33404

Unclas

$63 / 05 \quad 0117475$

September 1992

National Aeronautics and

Space Administration 
8. 


\section{The F-18 High Alpha Research Vehicle: A High-Angle-of-Attack Testbed Aircraft}

Victoria Regenie and Donald Gatlin NASA Dryden Flight Research Facility Edwards, California

Robert Kempel

PRC Inc.

Edwards, California

Neil Matheny

NASA Dryden Flight Research Facility

Edwards, California

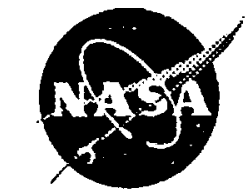

National Aeronautics and

Space Administration

Dryden Flight Research Facility Edwards, California 93523-0273 


\title{
THE F-18 HIGH ALPHA RESEARCH VEHICLE: A HIGH-ANGLE-OF-ATTACK TESTBED AIRCRAFT
}

\author{
Victoria Regenie* and Donald Gatlin** \\ NASA Dryden Flight Research Facility \\ Edwards, California \\ Robert Kempel ${ }^{\dagger}$ \\ PRC Inc. \\ Edwards, California \\ Neil Matheny ${ }^{\ddagger}$ \\ NASA Dryden Flight Research Facility \\ Edwards, California
}

\begin{abstract}
The F-18 High Alpha Research Vehicle is the first thrust-vectoring testbed aircraft used to study the aerodynamics and maneuvering available in the poststall flight regime and to provide the data for validating ground prediction techniques. The aircraft includes a flexible research flight control system and full research instrumentation. The capability to control the vehicle at angles of attack up to $70^{\circ}$ is also included. This aircraft was modified by adding a pitch and yaw thrust-vectoring system. No significant problems occurred during the envelope expansion phase of the program. This aircraft has demonstrated excellent control in the wing rock region and increased rolling performance at high angles of attack. Initial pilot reports indicate that the increased capability is desirable although some difficulty in judging the size and timing of control inputs was observed. This paper describes the aircraft, preflight ground testing, and envelope expansion flight tests.
\end{abstract}

\section{Nomenclature}

\section{Abbreviations}

AB

$\mathrm{A} / \mathrm{D}$

CFD

$\mathrm{D} / \mathrm{A}$

DPRAM

$$
\text { afterburner }
$$$$
\text { analog to digital }
$$$$
\text { computational fuid dynamics }
$$$$
\text { digital to analog }
$$$$
\text { dual-port random-access memory }
$$

\footnotetext{
*Aerospace engineer.

** High Alpha Research Project Manager.

'Senior Aerospace Engineer.

${ }^{\ddagger}$ Chief, Flight Dynamics Section.

Copyright (C) 1992 by the American Institute of Aeronautics and Astronautics, Inc. No copyright is asserted in the United States under Title 17, U.S. Code. The U.S. Government has a royalty-free license to exercise all rights under the copyright claimed herein for Governmental purposes. All other rights are reserved by the copyright owner.
}

EEPROM electrically erasable programmable readonly memory

FCS flight control system

F.S. fuselage station

GE General Electric, Lynn, Massachusetts

HARV High Alpha Research Vehicle

HATP High Alpha Technology Program

HUD head-up display

INS inertial navigation system

LEX leading-edge extension

MIL-STD military standard

OBES on-board excitation system

RFCS research flight control system

TVCS thrust-vectoring control system

UART universal asynchronous receivertransmitter

UVPROM ultraviolet programmable read-only memory

Symbols

$g$

$p \quad$ yaw rate, $\operatorname{deg} / \mathrm{sec}$

$r \quad$ roll rate, $\mathrm{deg} / \mathrm{sec}$

$\alpha \quad$ angle of attack, deg

$\beta \quad$ angle of sideslip, deg

$\phi \quad$ pitch rate, $\operatorname{deg}$

\section{Introduction}

Recently, aircraft designers and research organizations have focused attention on extreme maneuverability to enable fighter aircraft to obtain a tactical advantage. On the other hand, lack of validated design criteria for establishing maneuverability requirements has limited the exploitation of this technology. 
High-angle-of-attack flight research has not received the same in-depth attention as prestall tactical fight regimes for the fighter-aircraft mission. Until recently, lack of suitable ground and flight test facilities has also inhibited progress in this area. In addition, the highly nonlinear nature of fighter dynamics in the post-stall flight regimes has complicated theoretical analyses.

The NASA High Alpha Technology Program (HATP) was created to accelerate maturation of such developing technologies as aerodynamics, computational fluid dynamics (CFD), controls, and propulsion in this regime. The HATP merges these technologies into credible design tools. The F-18 High Alpha Research Vehicle (HARV) was created to provide the HATP with a versatile test aircraft capable of providing high quality data without the limitations of scale, rate, and Reynolds number found in the wind tunnel. ${ }^{1}$ This aircraft has proven to be the research catalyst that was envisioned by providing an exciting opportunity for concurrent flight and ground research activities.

The initial phase of the program concentrated on the vortical flow aerodynamics of the HARV at angles of attack up to $50^{\circ}$. This research primarily concentrated on flow visualization, surface pressures measured on the forebody and leading-edge extension (LEX), and airdata. ${ }^{2-16}$ Thrust-vectoring turning vanes were added to the HARV to provide increased high-angle-ofattack maneuverability. The aircraft is now capable of trimming at an angle of attack of $70^{\circ}$. Rolling rates at high angles of attack have been significantly increased. A flexible flight control system and expanded instrumentation were added to provide a flexible platform for high-angle-of-attack research. This paper describes the HARV with its extensive instrumentation and control capabilities, presents a sample of results to date, discusses lessons learned during development, and forecasts future research activities.

\section{Vehicle Description}

This section describes the aircraft configuration, control systems, and instrumentation.

\section{Configuration}

Figure 1 shows the F-18 HARV. This vehicle is a modified full-scale developmental, twin-engine, singleplace, F-18 fighter-attack aircraft. Built by the McDonnell Douglas (St. Louis, Missouri) and Northrop (Newbury Park, California) Corporations for the U.S. Navy, this aircraft is powered by two modified F404GE-400 afterburning turbofan engines (General Electric, Lynn, Massachusetts) rated at approximately $16,000 \mathrm{lb}$ static thrust at sea level. This aircraft was modified by putting thrust-vectoring vanes in the engine exhaust to provide additional pitching and yawing moments. The divergent flap portion of the nozzle was removed from the engine to accommodate the thrustvectoring vane installation. Controlled movement of three externally mounted vanes on each engine provides thrust-vectoring capability. These vanes deflect the engine exhaust plume.

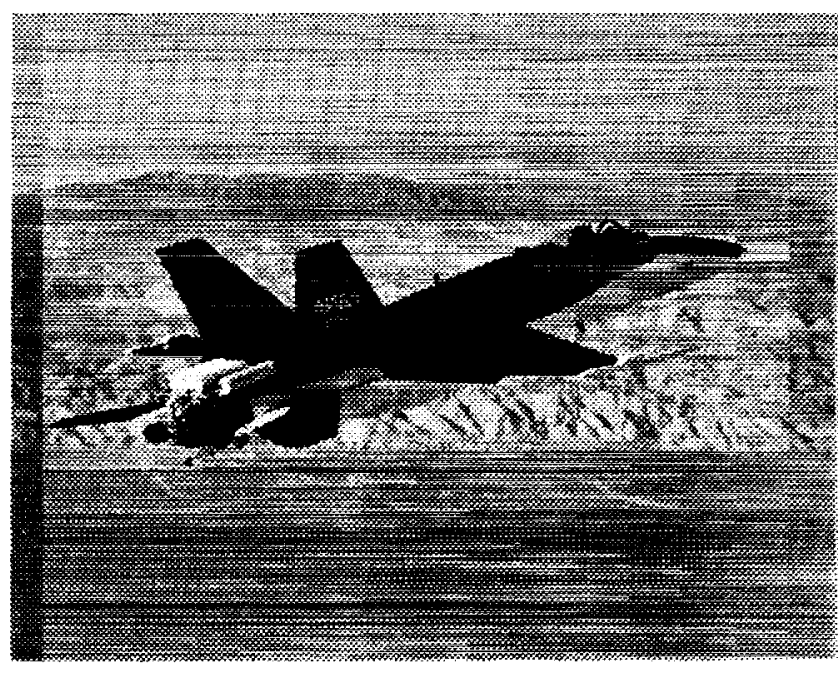

EC 910028-5

Fig. 1 The F-18 High Alpha Research Vehicle.

The HARV features a midwing configuration with a wing root LEX that extends from the forward portion of the fuselage and blends into the wing. The HARV carries no external stores and is highly instrumented for research purposes. Wingtip launching rails and missiles were replaced with specially designed camera pods and airdata sensors. A pilot-actuated spin chute has been provided should an unrecoverable spin occur. The inflight-refueling capability and the tail-arresting hook were retained.

\section{Aerodynamic Control Surfaces}

The five pairs of aerodynamic control surfaces include stabilators, rudders, ailerons, leading-edge flaps, and trailing-edge flaps. Twin vertical stabilizers with trailing-edge rudders are canted outboard at approximately $20^{\circ}$ from vertical. The all-movable horizontal stabilators operate collectively, and symmetric leadingand trailing-edge flaps provide pitch control. Roll control can use differential stabilator, ailerons, and asymmetric leading- and trailing-edge flaps. Symmetric rudder deflection provides directional control. In the power-approach configuration, symmetric aileron droop and rudder toe-in are employed. A speed brake is located on the upper aft fuselage between the vertical stabilizers. Table 1 presents the maximum surface position and rate limits. 
Table 1. F-18 High Alpha Research Vehicle aerodynamic and rate limits for a single surface.

\begin{tabular}{lcc}
\hline \hline Surface & $\begin{array}{c}\text { Position limit, } \\
\text { deg }\end{array}$ & $\begin{array}{c}\text { Rate limit, } \\
\mathrm{deg} / \mathrm{sec}\end{array}$ \\
\hline $\begin{array}{l}\text { Stabilator trailing } \\
\text { edge: }\end{array}$ & & \\
Up & 24 & 40 \\
Down & 10.5 & \\
Aileron trailing & & \\
edge: & & \\
Up & 25 & 100 \\
$\quad$ Down & 45 & \\
Rudder trailing & & \\
edge: & & \\
Left & 30 & 82 \\
Right & 30 & \\
Trailing-edge flap: & & \\
Up & 8 & 18 \\
Down & 45 & \\
\hline
\end{tabular}

Table 1. Concluded.

\begin{tabular}{ccc}
\hline Surface & $\begin{array}{c}\text { Position limit, } \\
\text { deg }\end{array}$ & $\begin{array}{c}\text { Rate limit, } \\
\text { deg/sec }\end{array}$ \\
\hline $\begin{array}{c}\text { Leading-edge flap: } \\
\text { Up }\end{array}$ & 3 & 15 \\
Down & 33 & \\
$\begin{array}{c}\text { Speed brake, } \\
\text { trailing edge up }\end{array}$ & 60 & 20 to 30 \\
\hline \hline
\end{tabular}

\section{Emergency Spin, Departure, or Both Recovery Systems}

The emergency spin, departure, or both recovery systems consist of the battery-powered electrical and hydraulic systems and a spin-recovery chute system. Figure 2 shows the location of the spin-recovery chute on the aft fuselage. These systems provide hydraulic and electrical power for flight control systems, emergency fuel boost, and essential avionics and instrumentation

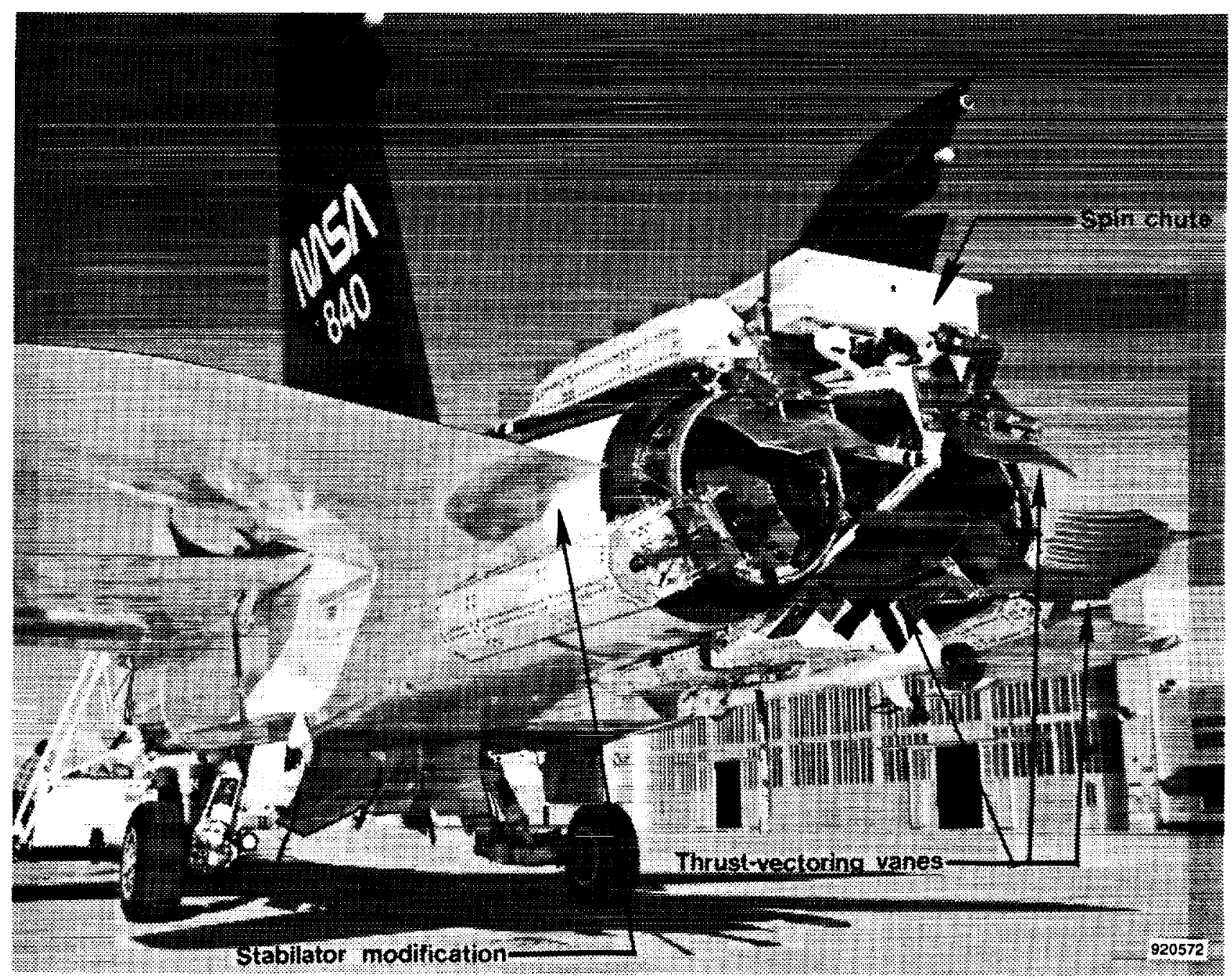

Fig. 2 Thrust-vectoring vanes, spin chute, and modified stabilator. 
for the dual-engine-out condition. The spin-recovery chute operates independently of the emergency power functions.

\section{Thrust-Vectoring Vane System}

In general, the thrust-vectoring vane system was positioned to avoid interference with the aerodynamic control surfaces; however, the inside trailing edges of the stabilators were notched slightly to provide lower outboard vane-actuator-housing clearance (Fig. 2). Each stabilator was reduced by $0.89 \mathrm{ft}^{2}$, leaving an area of $43.24 \mathrm{ft}^{2}$. This modification has not significantly reduced stabilator effectiveness. Figures 2 and 3 show that the thrust-vectoring vanes are positioned about the periphery of the engine and behind the nozzle exits. The dashed lines in Fig. 3 show the nozzle area for the military and maximum afterburner $(\mathrm{AB})$ power settings.

\section{Vane deflection}

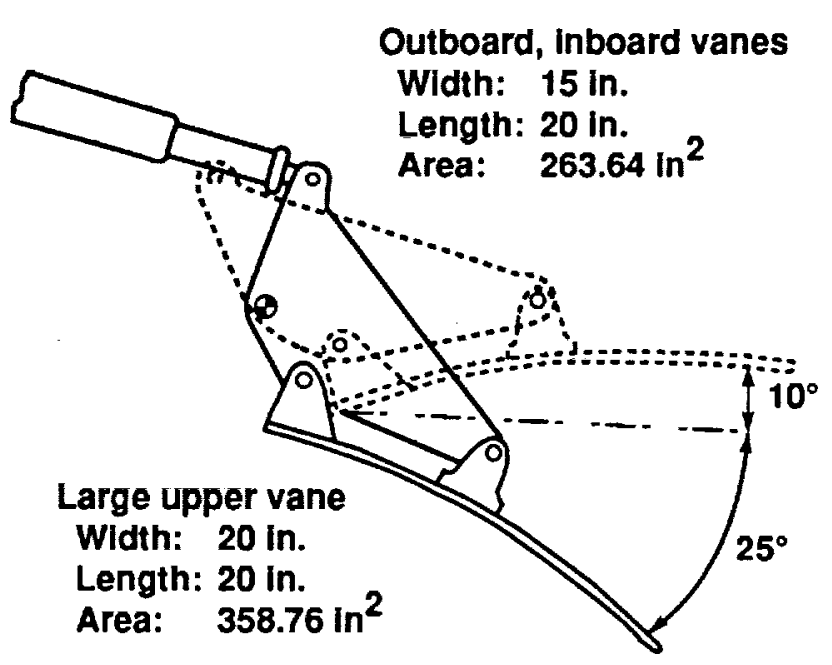

Nozzle geometry

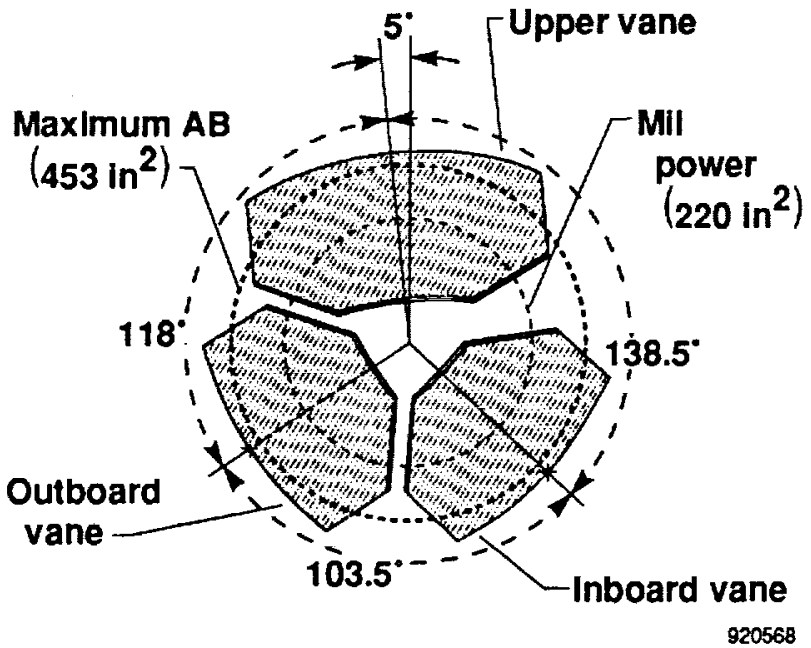

Fig. 3 The F-18 High Alpha Research Vehicle thrustvectoring system.
Table 2 lists the specifications for the thrustvectoring vanes. The corners of each vane were clipped to avoid interference with adjacent vanes at full deflection. Modified aileron electrohydraulic actuators provide vane actuation. Each vane was machined from a single billet of Inconel 625.* This thrust-vectoring vane installation weighs approximately $2200 \mathrm{lb}$, including $700 \mathrm{lb}$ of ballast to maintain the nominal F-18 center-of-gravity position. Installation of the spin chute, emergency systems, and associated ballast also added $1500 \mathrm{lb}$. The weight increase because of the thrust-vectoring control and emergency systems totaled approximately $3700 \mathrm{lb}$. Table 3 lists the physical characteristics of the HARV.

Table 2. Thrust-vectoring vane system specifications.

\begin{tabular}{lc}
\hline \hline Parameter & Value \\
\hline Vane: & \\
Size, in.: & $20 \times 20$ \\
Upper & $20 \times 15$ \\
Lower & \\
Area, in ${ }^{2}:$ & 358.76 \\
Upper & 263.64 \\
Lower & -10 to 25 \\
Position limit, deg & 80 \\
Rate limit, deg/sec & 2200 \\
TVCS, lb & \\
Load factor limit, $g:$ & 5.4 \\
Symmetric & 4.3 \\
Asymmetric
\end{tabular}

The engines were modified to accommodate the thrust-vectoring vane installation by removing the divergent flap portion of the nozzle. The remaining convergent nozzle hardware was modified to maintain structural integrity. In addition, the engine control unit was modified to provide the pilot with a selectable turbine-discharge temperature bias control to increase the engine-stall margin, if required. An increase in engine-stall margin of 3.5 and 7 percent is selectable with a cockpit-mounted switch. This modification resulted in a thrust reduction at maximum $A B$ of approximately 4 and 9 percent.

Electrical and hydraulic modifications to accommodate the TVCS were minimal. Hydraulic power for the vane actuators was supplied by $\mathrm{T}$-connections to the existing right- and left-side hydraulic systems of the aircraft upstream of the switching valves to the rudder and stabilator. Sufficient hydraulic capacity was available without modification. Electrical wire bundles from the vane system were routed through the upper

\footnotetext{
"Inconel 625 is a registered trademark of the Huntington Alloy Products Division, International Nickel Company, Huntington, West Virginia.
} 
fuselage to interface with the computer and cockpit controls.

Table 3. Physical characteristics of the F-18 High Alpha Research Vehicle with thrust-vectoring control system and spin chute.*

\begin{tabular}{lc}
\hline \hline \multicolumn{1}{c}{ Parameter } & Value \\
\hline Length, ft & 56 \\
Weight, lb & 36,099 \\
Reference: & \\
$\quad$ Mean aerodynamic & \\
$\quad$ chord, $\mathrm{ft}$ & 11.52 \\
$\quad$ Span, $\mathrm{ft}$ & 37.4 \\
Wing: & \\
$\quad$ Area, $\mathrm{ft}^{2}$ & 400 \\
Aspect ratio & 3.5 \\
Center of gravity: & \\
$\quad$ Mean aerodynamic & \\
$\quad$ chord, \% & 23.8 \\
Fuselage reference, $\mathrm{ft}$ & 456.88 \\
$\quad$ Water line, $\mathrm{ft}$ & 105.35 \\
Inertias, slug- $\mathrm{ft}^{2}$ : & \\
Roll & 22,789 \\
Pitch & 176,809 \\
Yaw & 191,744 \\
Product & $-2,305$ \\
Stabilator: & \\
Span, $\mathrm{ft}$ & 21.6 \\
Area, $\mathrm{ft}^{2}$ & 86.48 \\
\hline \hline
\end{tabular}

"The fuel weighs $6480 \mathrm{lb}$, which represents an approximately 60 percent fuel condition. These data are for the gear-up and clean configuration with pilot and support equipment.

\section{Flight Control System and Avionics}

The quad-redundant GE $701 \mathrm{E}$ computers of the basic F-18 flight control system were modified for HARV. Two new elements, an analog interface to the thrustvectoring vane actuators and a research flight control system (RFCS), were added. An analog interface card and the RFCS were installed in spare card slots in the basic flight control computer chassis. The basic fight control computer maintains control of the aircraft and all input, output, or both processing functions. The RFCS communicates with the GE 701E computer using the dual-port random-access memory (DPRAM) and has no direct communication to the aircraft.

Figure 4 shows the conceptual diagram for the flight control computer architecture. This architecture allows RFCS software to be classified as non-safety-offlight; therefore, less intensive qualification tests are required. The research flight control computer uses a Pace 1750A processor (Performance Semiconductor Corporation, Sunnyvale, California). Programmed in
Ada, this processor is slaved to the GE $701 \mathrm{E}$ computer. The basic flight control system communicates outer loop control and display information to the F-18 mission computer through a military standard (MILSTD) 1553 bus. The Pace $1750 \mathrm{~A}$ and GE $701 \mathrm{E}$ computers calculate the control law functions at $80 \mathrm{~Hz}$. Programmed in assembly language, the basic flight control computer software was extensively modified by GE to allow communication with the RFCS. The basic control laws remain functionally identical to the standard production system. Other researchers have described these flight control and avionics systems and their testing in great detail. ${ }^{17}$

Two features included in the RFCS development provide a flexible system that can expedite flight research: the capabilities to monitor internal control system parameters and to change the software easily. The RFCS stores internal information on two messages that are transmitted to the GE $701 \mathrm{E}$ at $80 \mathrm{~Hz}$. These messages are then passed by the MIL-STD-1553 bus to the instrumentation system for monitoring. Use of Ada allows quick modifications to the RFCS code. Required testing of non-flight-critical software is not extensive. Constants can be changed within 1 day.

The mission computer provides the interface between the flight control computers, sensors, and cockpit digital display indicators. These indicators show the pilot primary flight information and systems status and announce cautions, failures, or both. To accomplish this task, the mission computer controls the MIL-STD1553 multiplex bus. This multiplex data bus provides an integrated communications system and a standard interface for all equipment connected to the bus. Furthermore, this bus provides a point at which bus traffic is available for access by monitoring instrumentation or recording systems.

Modifications to the mission computer software were required to support the expanded capabilities of the RFCS. Algorithms were implemented in the mission computer to calculate control system parameters not previously available. The production angle-of-attack probes are physically limited at the sensors to $34^{\circ}$. To provide a signal above $34^{\circ}$, the angle of attack is calculated in the mission computer from the inertial navigation system (INS) data. Angle-of-sideslip $\beta$ rate is also a primary feedback signal in the RFCS and is, likewise, computed from INS inputs. In addition, impact and static pressure calculated from airdata and INS inputs are provided. Engine data used in the RFCS thrust estimator to modify thrust-vane commands are provided through the mission computer. Angle-of-sideslip and -attack rate data are also calculated from INS data for possible future use. These parameters are sent from the mission computer through the MIL-STD-1553 bus 


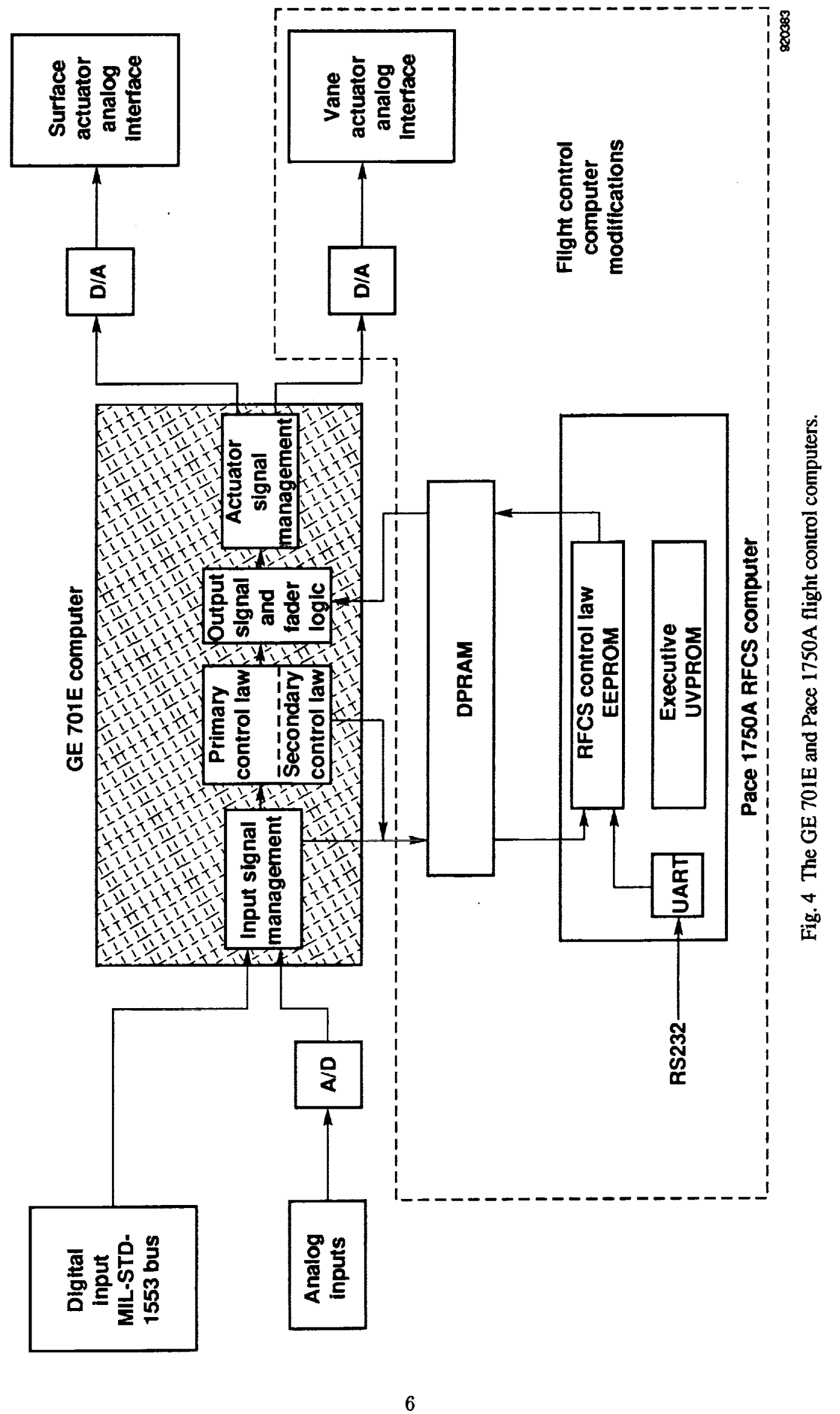


to the basic flight control computer. Then, the parameters are sent to the RFCS.

The angle-of-attack and -sideslip rates are checked to determine if the values calculated by the mission computer and sent to the RFCS are reasonable. The mission computer sends bus data to two flight control computers. These data are data-linked between the basic flight control computers and sent to DPRAM. The RFCS compares the two sets of data to ensure that all systems use the same data.

Control laws for the RFCS were designed to provide steady-state angle-of-attack control and large amplitude-maneuvering capability at high angles of attack. $^{18}$ The steady-state capability was given higher priority than large amplitude control in the design process. The longitudinal axis is an angle-of-attack command system that feeds back angle-of-attack and pitch rate. The product of angular velocities is used to reduce inertial coupling. The control stick is geared to provide an angle of attack of $70^{\circ}$ at 5 in. of aft deflection. This control system selects the measured angle of attack if it is less than $25^{\circ}$. The calculated angle is selected if the aircraft angle of attack is greater than $30^{\circ}$. The control system fades between the two angles from $25^{\circ}$ to $30^{\circ}$.

An inertial decoupling feedback is used to alleviate the inertial coupling in pitching moment generated by high roll rates. This feedback uses the product of roll and yaw angular rate through a gain scheduled with airdata parameters. The lateral-directional axis was designed using an eigenstructure assignment approach and provides a feet-on-the-floor stability axis roll rate command capability. This system uses roll, sideslip, and yaw rates; lateral acceleration; and inertial coupling as feedback signals.

An on-board excitation system (OBES) was incorporated in the RFCS to excite structural modes through surface deflection and allow single aerodynamic surface and thrust-vectoring vane movement for parameter identification. The OBES can command 31 combinations of surface-motion options. The driving functions can be changed by modifying the Ada code.

Control laws generate a thrust-vectoring angle command which a mixer in the RFCS converts into individual vane commands. This mixer uses estimated thrust, nozzle area and pressure ratio, and other vane positions to calculate vane commands. The thrust estimator uses nozzle area and pressure ratio, power level angle, and ambient pressure to calculate gross thrust.

\section{Cockpit and Pilot Controls}

The HARV cockpit displays include minor modifications to those of a standard F-18 aircraft. The most visible change involves addition of four analog gauges.
Figure 5 shows these gauges mounted on either side of the head-up display (HUD) to show angles-of-attack and -sideslip, normal acceleration, and yaw rates. The RFCS- and OBES-engaged indications were added to the HUD. In addition, the HUD includes vertical and horizontal needles driven by an uplink system to assist the pilot in maintaining flight conditions. ${ }^{19}$

The HARV retains the basic F-18 cockpit controls; however, additional switches were added to arm the RFCS, control the variable-engine-stall-margin bias, and activate the emergency systems. Switches on the stick grip command pitch and roll trim. A multifunction paddle switch, located just below the grip, is used to command RFCS disengage. This switch also disengages the autopilot when in GE $701 \mathrm{E}$ modes and the nose wheel steering when on the ground. Table 4 lists the pilot's stick and rudder pedal position limits, force gradients, and break-out forces. Feel springs provide stick- and rudder-force gradients.

Table 4. F-18 High Alpha Research Vehicle pilot's cockpit control characteristics.

\begin{tabular}{lccc}
\hline \hline Control & $\begin{array}{c}\text { Position } \\
\text { limit, in.* }\end{array}$ & $\begin{array}{c}\text { Force gradient } \\
\text { lb/in. }\end{array}$ & $\begin{array}{c}\text { Break-out } \\
\text { force, lb }\end{array}$ \\
$\begin{array}{c}\text { Stick pitch: } \\
\text { Aft }\end{array}$ & 5.00 & 8.0 & 3 \\
$\quad$ Forward & 2.50 & 8.6 & 3 \\
$\begin{array}{c}\text { Lateral: } \\
\text { Left and } \\
\text { right }\end{array}$ & 3.0 & 4.3 & 2 \\
$\begin{array}{c}\text { Rudder pedal: } \\
\text { Left and } \\
\text { right }\end{array}$ & 1.0 & 100 & 7 \\
\hline \hline
\end{tabular}

${ }^{*}$ Stick positions are measured at the grip neutral point on an 18.50 in. radius from the pivot point.

\section{Instrumentation}

The instrumentation on the HARV includes parameters from the production F-18 MIL-STD-1553 data bus and specialized instrumentation installed for flight research. This specialized instrumentation includes 75 thermocouples and 14 strain gauges on the thrust-vectoring system for monitoring temperatures and loads. Figure 6 shows the 383 static pressure orifices located on the forebody and LEX for pressure distribution measurements. Off-surface flow visualization of the forebody and LEX vortical flow are obtained using a smoke generation system that emits particles at the nose tip and the LEX apex. ${ }^{20}$ Four video cameras and one still camera are used to photograph the flow. Surface flow visualization is obtained using an emitted fluid technique. ${ }^{21}$ Flow visualization and pressure data are used to correlate and validate CFD and wind-tunnel results. 


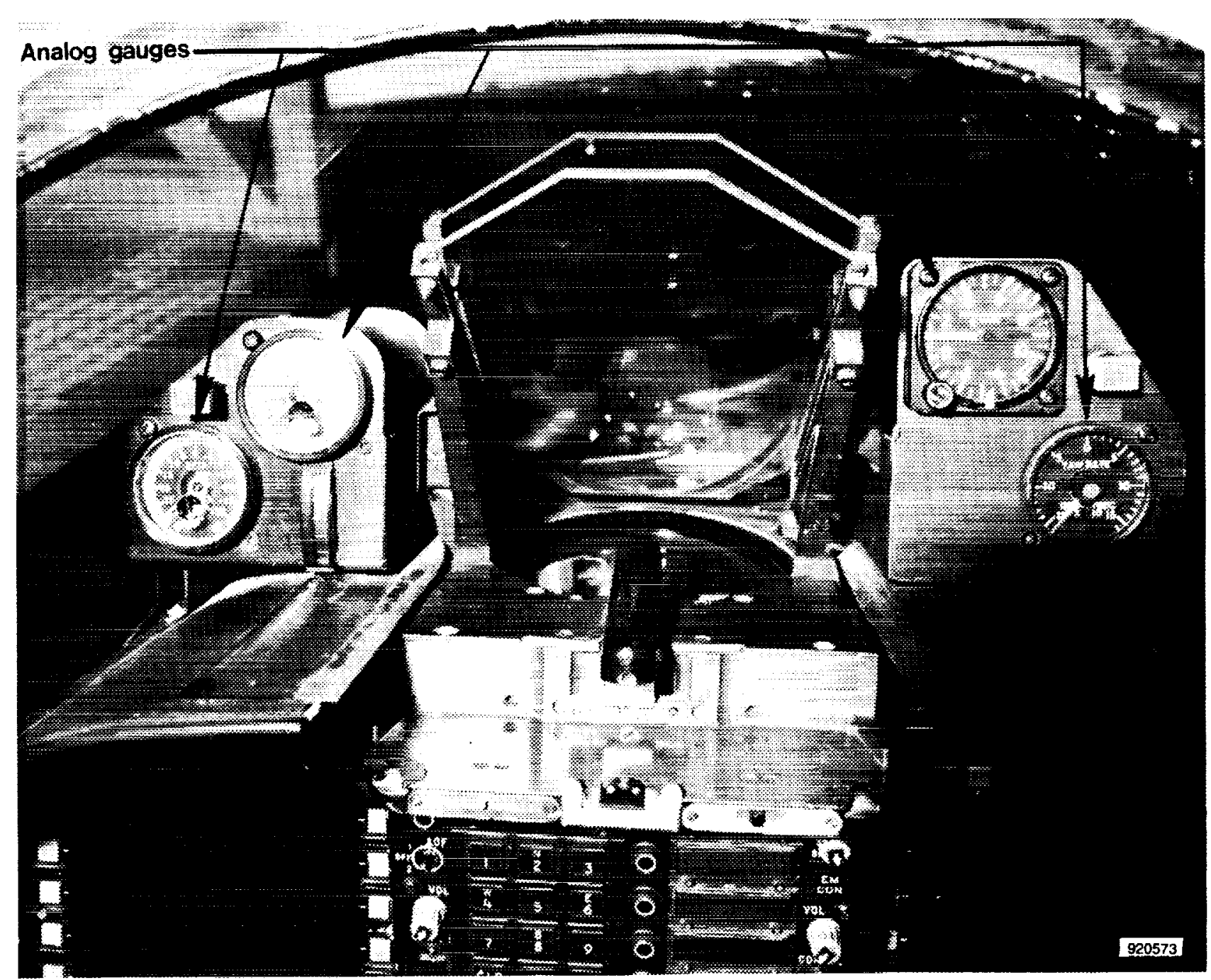

Fig. 5 The F-18 High Alpha Research Vehicle cockpit modifications.

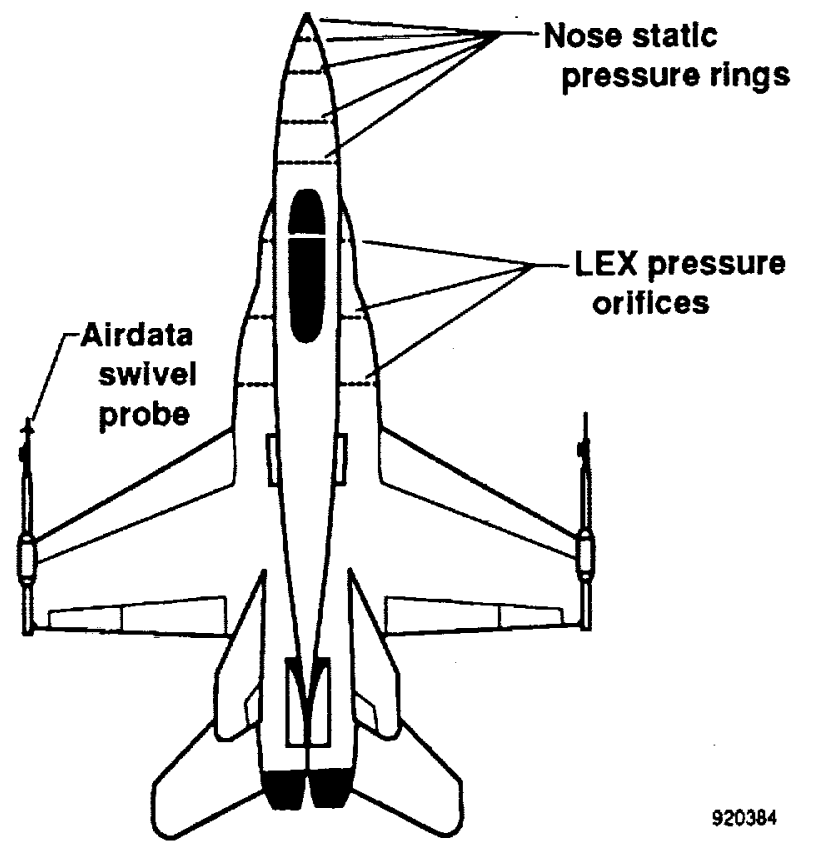

Fig. 6 Airdata and pressure measurement systems.
Both engines have basic instrumentation for monitoring engine operation and are equipped with a realtime thrust measurement system. The right engine has additional instrumentation for engine and inlet diagnostics with 63 pressure measurements. An inlet rake with 40 high-response pressure sensors to be installed at the right engine face is currently in development and will allow measurement of inlet distortion at high angles of attack. The data from the inlet rake along with sensors installed in the inlet will be used to spot-check CFD predictions.

Aircraft-response instrumentation includes accelerometers, rate gyros, surface-position measurements, and airdata. Data monitored from the MIL-STD-1553 bus include 226 flight control system, 21 airdata computer, 37 engine and aircraft diagnostic, and 32 INS parameters. Two high-angle-of-attack flight research airdata systems were developed. Swiveling pitot probes with conventional angle-of-attack and -sideslip vanes are mounted on both wingtips and are used for cockpit 
display. ${ }^{13}$ A flush airdata system is used for postflight data. $^{12}$

\section{Results and Discussion}

Ground and flight tests are described next. In addition, the results of selected tests are given.

\section{Ground Test}

Thorough preflight ground testing of the HARV systems was completed to minimize discovery of potential anomalies during flight. Ground testing included individual and combined systems tests. A ground vibration test was completed to define the changes in the aircraft structural modes. Structural modifications were tested on the aircraft through proof and hot loads tests. The proof load tests were used to calibrate the strain gauges on the vane assemblage and to determine the load levels acceptable for flight. During hot loads testing, the engine exhaust was used to generate vane loads at nearly flight temperatures. Data were collected from the calibrated strain gauges along with the temperatures on the vane and spin chute assemblage to predict flight conditions. Infrared photography was used to measure vectoring angles. Figure 7 shows the engine exhaust vectored up during the hot loads test. Axial thrust loss caused by thrust vectoring was measured and compared with ground test results. ${ }^{7}$
The flight control systems and mission computer were qualified in the simulation facility. This facility consists of three real-time simulations: an all-software, an electronic hardware-in-the-loop, and an iron bird. The all-software simulation incorporates the mission computer and is used for pilot training, flight test planning, and control law development. The hardware-inthe-loop and iron bird incorporate simulation, flight control, and mission computers as well as the avionics hardware and a cockpit.

In the hardware-in-the-loop simulation, control laws modeled in the simulation computer and the workstation in the all-software version are replaced by control laws operating in the flight control computers. This version is also used for pilot training, flight test planning, and engineering development.

In the iron bird, hydraulically powered actuators and surfaces installed in a nonflyable F-18 aircraft replace the analog models used for the hardware-in-the-loop simulation. The leading- and trailing-edge flaps are inoperable. Iron bird simulation is used as a final check for the system configuration.

Batch simulation is also available on a workstation and is considered an initial proof model for all modifications of new control laws. The control law designs are refined using the batch simulation. Results

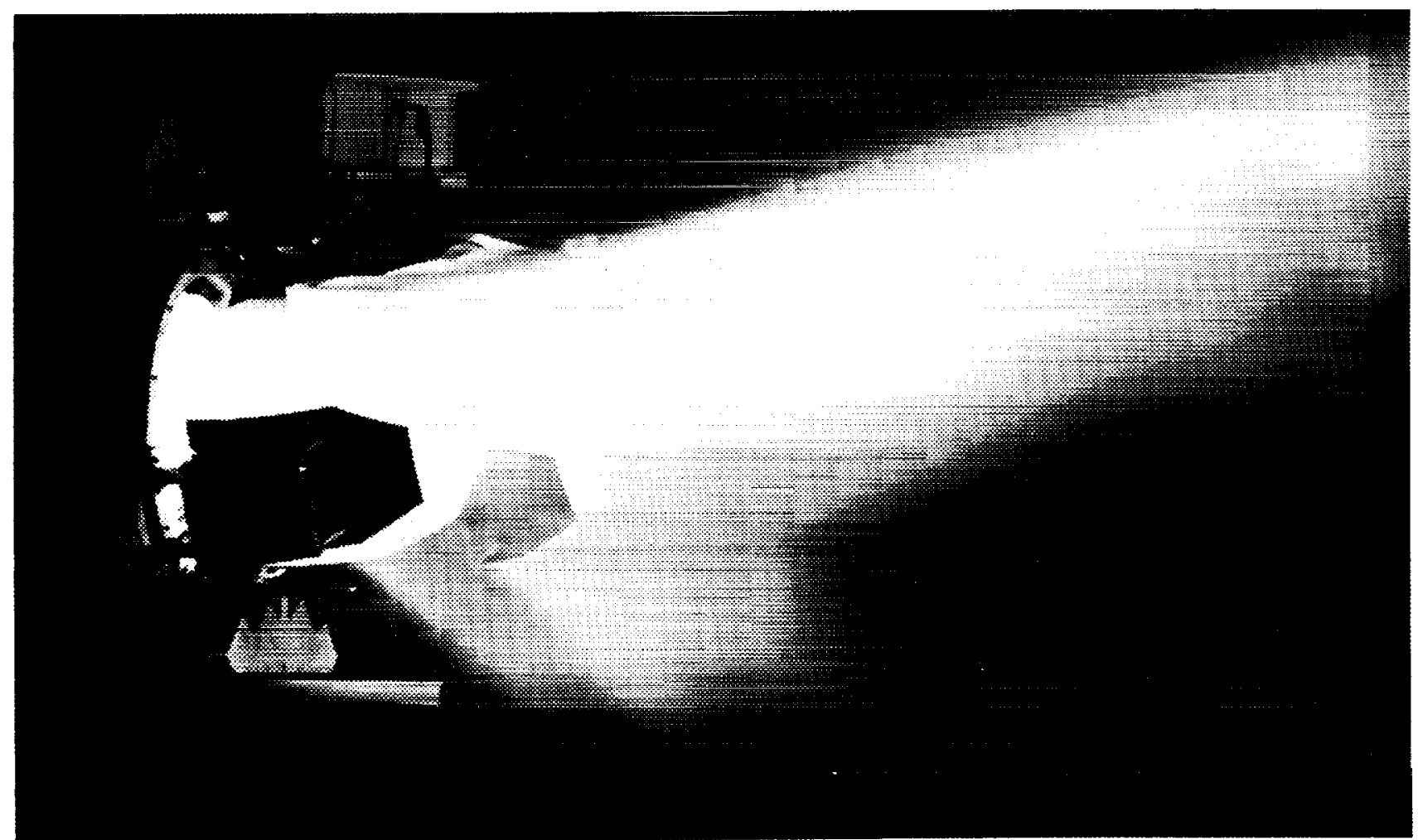

EC90 0075-20

Fig. 7 Vectored thrust during hot loads. 
from the real-time simulations using flight software are compared with the batch simulator results. Such thorough testing of the flight software, including hardwarein-the-loop and iron bird simulations, is the major reason that few anomalies were discovered in flight.

\section{Flight Test}

Flight test results with thrust vectoring have been very favorable. The HARV has completed 139 flights to date. Thirty-eight of these flights were completed with the thrust-vectoring system installed. The TVCS envelope expansion phase was completed between July 1991 and February 1992. This phase included demonstration of steady flight at an angle of attack of $70^{\circ}$ and $360^{\circ}$ stability axis rolls between angles of attack of $25^{\circ}$ and $65^{\circ}$. Thrust vectoring allowed controlled flight at higher angles of attack than the conventional F-18 aircraft with standard nozzles. Figure 8 shows the stabilized flight envelope with and without thrust vectoring. The HARV can fly stably at slightly more than an angle of attack of $30^{\circ}$. In this figure, the small region near an angle of attack of $50^{\circ}$ indicates an area where wing rock diminishes in magnitude, and the aircraft is minimally stable. No significant problems occurred during the 38 flights with $71 / 3 \mathrm{hr}$ of in-flight TVCS operation.

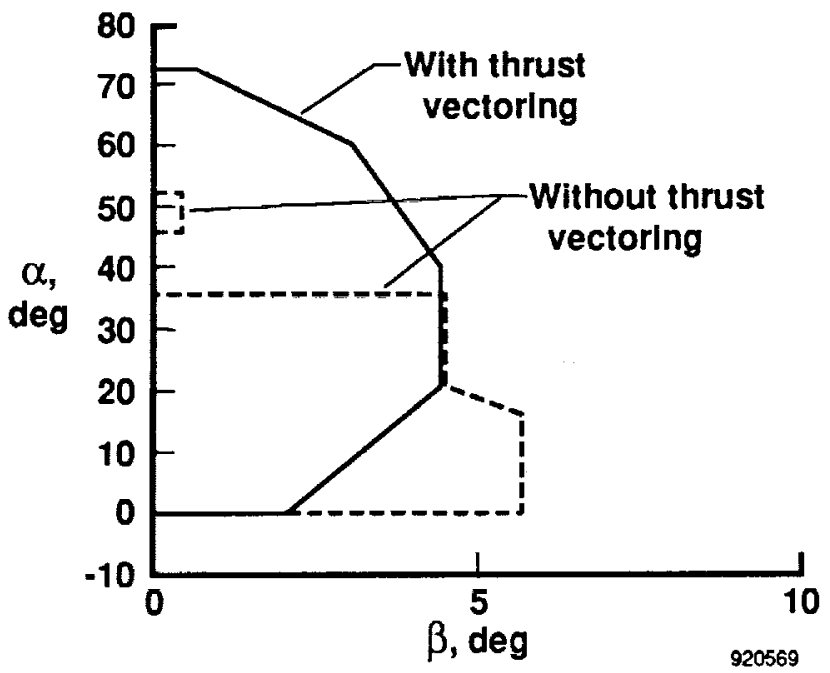

Fig. 8 Angle-of-attack and -sideslip envelope with and without thrust vectoring.

Deficiencies identified in flight tests resulted in six RFCS software releases as of March 1992. Modifications in these releases ranged from minor error corrections to installation of the OBES. The majority of the code modifications reduced nuisance down modes in-flight from the RFCS to the basic flight control system and changed the parameters that the instrumentation system monitored on the data bus.
Extensive aeroservoelastic analysis and testing were done during the envelope expansion phase. The analysis assumed a structural damping ratio of at least 0.02 , and no instabilities were predicted within the flight envelope. ${ }^{23}$ At high angles of attack, the natural buffet of the aircraft masks the modal dynamics and makes it very difficult to evaluate the aeroservoelastic margins without an external excitation system. The OBES was designed and developed to excite the aircraft natural structural frequencies by driving an aerodynamic or thrust-vane control surface with a sine wave frequency sweep. Results from the aeroservoelastic clearance using the OBES showed good agreement between the analysis and flight test results. Further research is planned to improve techniques for exciting the structural modes to allow calculation of the phase and gain margins of the elastic modes from flight test data.

The TVCS was used to obtain higher pitch, roll, and yaw rates than those attainable with the basic F-18 aircraft. Initially, high yaw rate maneuvers were flown to demonstrate the ability of the HARV to adequately recover without the use of thrust vectoring. Yaw rates exceeding $70 \mathrm{deg} / \mathrm{sec}$ have been measured. Even with the higher inertias caused by the added mass of the thrust vanes and emergency systems, the aircraft was fully recoverable by aerodynamic controls alone. ${ }^{24}$ At completion of envelope expansion in February 1992, no engine stalls had been observed with normal stallmargin control settings. The engines operated reliably at the high-angles-of-attack and other angular rate conditions tested. To date, all tests were conducted with fixed throttles.

The flight control laws are designed to command stability axis roll rate with lateral stick inputs. Figure 9 shows roll rates generated with and without thrust vectoring. These data are from the HARV fixed base simulation at maximum power with full lateral stick input held throughout the maneuver. In addition, these data represent the maximum rate attained in the first $90^{\circ}$ of stability axis bank angle. Nonvectored HARV rates are significantly reduced above $15^{\circ}$, and essentially no rolling performance occurs above $40^{\circ}$. Vectoring combined with the aerodynamic controls produces nearly constant rates at angles of attack between $20^{\circ}$ and $65^{\circ}$. The emphasis placed on vectoring performance at high angles of attack during the control law design process has resulted in a reduction in roll rate compared with the unmodified aircraft at low angles of attack. 


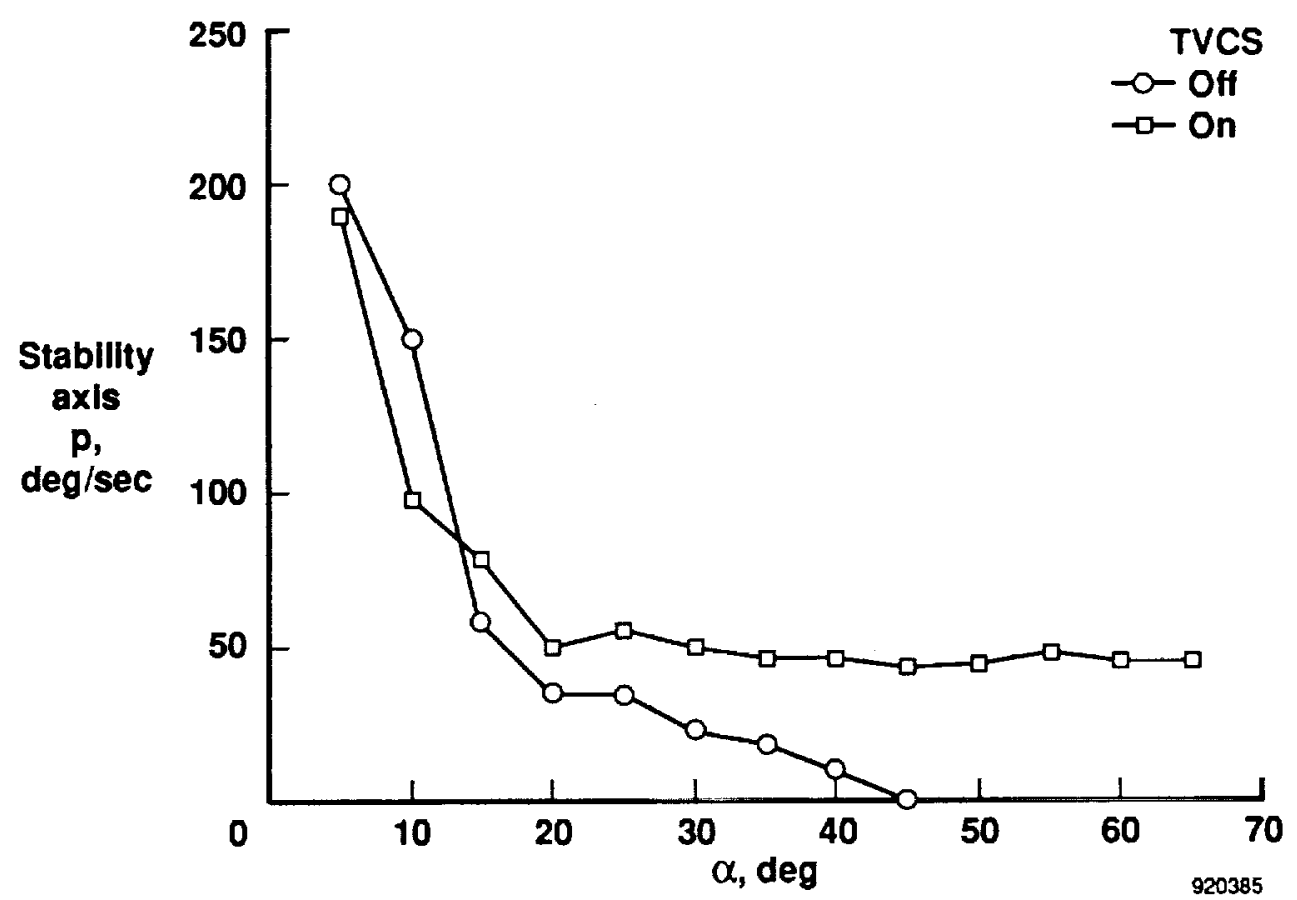

Fig. 9 stability axis roll rate as a function of angle of attack with simulation data maximum power at an altitude of $30,000 \mathrm{ft}$.

The performance benefit of thrust vectoring was also demonstrated in the region for angles of attack between $35^{\circ}$ and $50^{\circ}$, where the nonvectored aircraft experiences significant wing rock. Figure 10 shows that the HARV without thrust vectoring (RFCS off) experiences large, uncommanded oscillations in roll and sideslip at an angle of attack of $40^{\circ}$. Roll and yaw rates show similar uncommanded motion. Figure 11 shows that with the vectoring engaged (RFCS on) the roll and sideslip angle excursions are greatly reduced in amplitude, and little oscillatory motion occurs. Roll and yaw rates are similarly reduced.
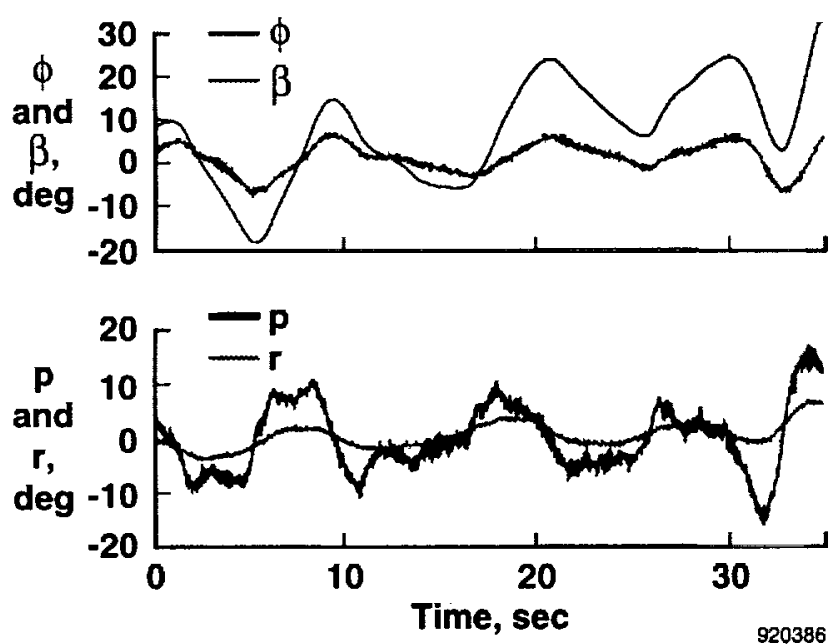

Fig. 10 Phase I, $40^{\circ}$-angle-of-attack wing rock with the research flight control system off.
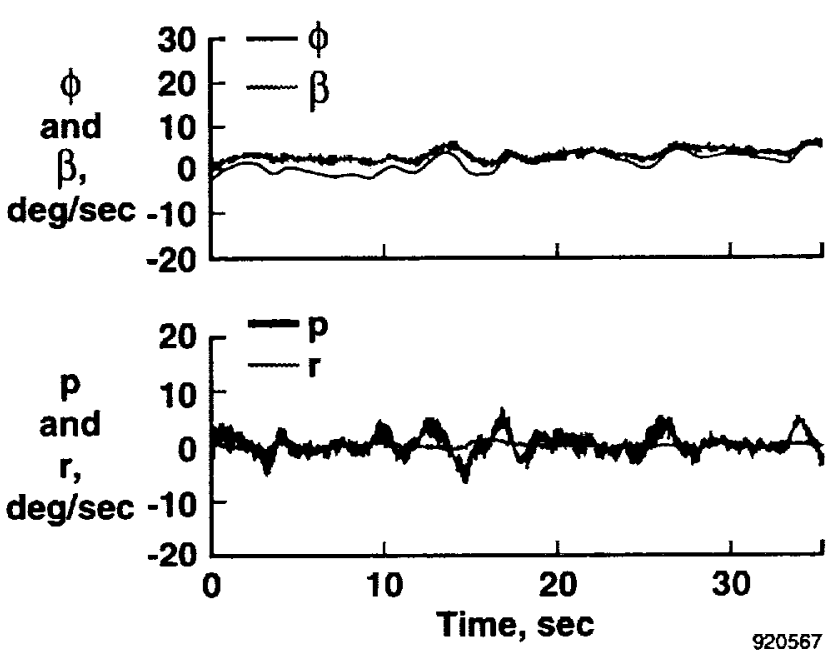

Fig. 11 Phase II, $40^{\circ}$-angle-of-attack wing rock with the research flight control system on.

Loads envelope expansion presented some difficulties. The worst case for vane attachment to fuselage loading occurred at maximum vane deflection with the aircraft at maximum normal load factor. On the other hand, the maximum normal load factors were achieved at angles of attack where the aerodynamic surfaces retain significant effectiveness. The RFCS control laws wash out the vanes if the aerodynamic surfaces have sufficient control power to satisfy the command. As a result, maximum vane deflection coincident with high normal load factor could only be achieved infrequently and as a transient. Trends of the limited flight data obtained indicate that no unexpected loads were 
generated. The current cleared normal load factor envelope is $5.4 \mathrm{~g}$ symmetric and $4.3 \mathrm{~g}$ asymmetric. Realtime monitoring of the flight loads will continue.

Typical pilot comments concerning the aircraft response with RFCS engaged were quite favorable. Such comments as "exhibited excellent pitch and roll control power throughout" and "exhibited tremendous pitching power while retaining precise positive roll control throughout the maneuver" were common. The pilot said that the aircraft "exhibits precise, powerful control in all axes during rolling maneuvers" for the angleof-attack region from $25^{\circ}$ to $45^{\circ}$. At angles of attack of $55^{\circ}$ and above, the pilot had difficulty estimating the timing and magnitude of the control input required to accurately complete such maneuvers as stability axis rolls at the desired attitude.

Difficulties in maintaining angle of attack while performing lateral-directional maneuvers at angles of attack for $65^{\circ}$ and $70^{\circ}$ points have been reported. The current control laws are designed to command a maximum angle of attack of $70^{\circ}$, but no pitch priority exists in these vane control laws. As a result, when maximum surface positions are required to maintain an angle of attack of $70^{\circ}$, lateral-directional control inputs will be subtracted and cause angle of attack to bleed off. Overall, the pilot noted that "the RFCS has restored the rolling capability lost above $25^{\circ}$ angle of attack in the basic F-18 aircraft." Preliminary flight dynamics results of the flight test program are available. ${ }^{25}$
The next phase of flight research involves measuring forebody and LEX pressures in the wing rock region and at angles of attack above $50^{\circ}$ using the TVCS to provide a stable platform. Data acquisition at steady angles of sideslip is now obtainable. Additional wing and tail pressure instrumentation and vortex flow investigations using smoke and emitted fluid techniques are planned for 1993. A laser light sheet is in development for use with the smoke to assist in visualization of the off-surface vortex structure.

A major modification to the HARV is also in development. The RFCS has sufficient flexibility and capability to drive additional control surfaces. The program is developing a pair of actuated forebody strakes to provide additional yawing moments for control in the medium- to high-angle-of-attack range. ${ }^{26}$ Figure 12 illustrates the placement of the actuated forebody strakes on the HARV. This system is scheduled to fly in 1994 as phase 3. The RFCS hardware will be modified to incorporate additional surface command signals. Existing control laws in the RFCS will be replaced with new software to simultaneously control the aerodynamic surfaces, thrust-vectoring vanes, and forebody strakes. These forebody strakes are expected to generate additional yawing moments. In addition, a pneumatic forebody vortex control system is being investigated in the wind tunnel using a full-scale $F-18$ aircraft as the model.$^{27}$ Figure 13 shows a conceptual diagram of a pneumatic forebody control system.

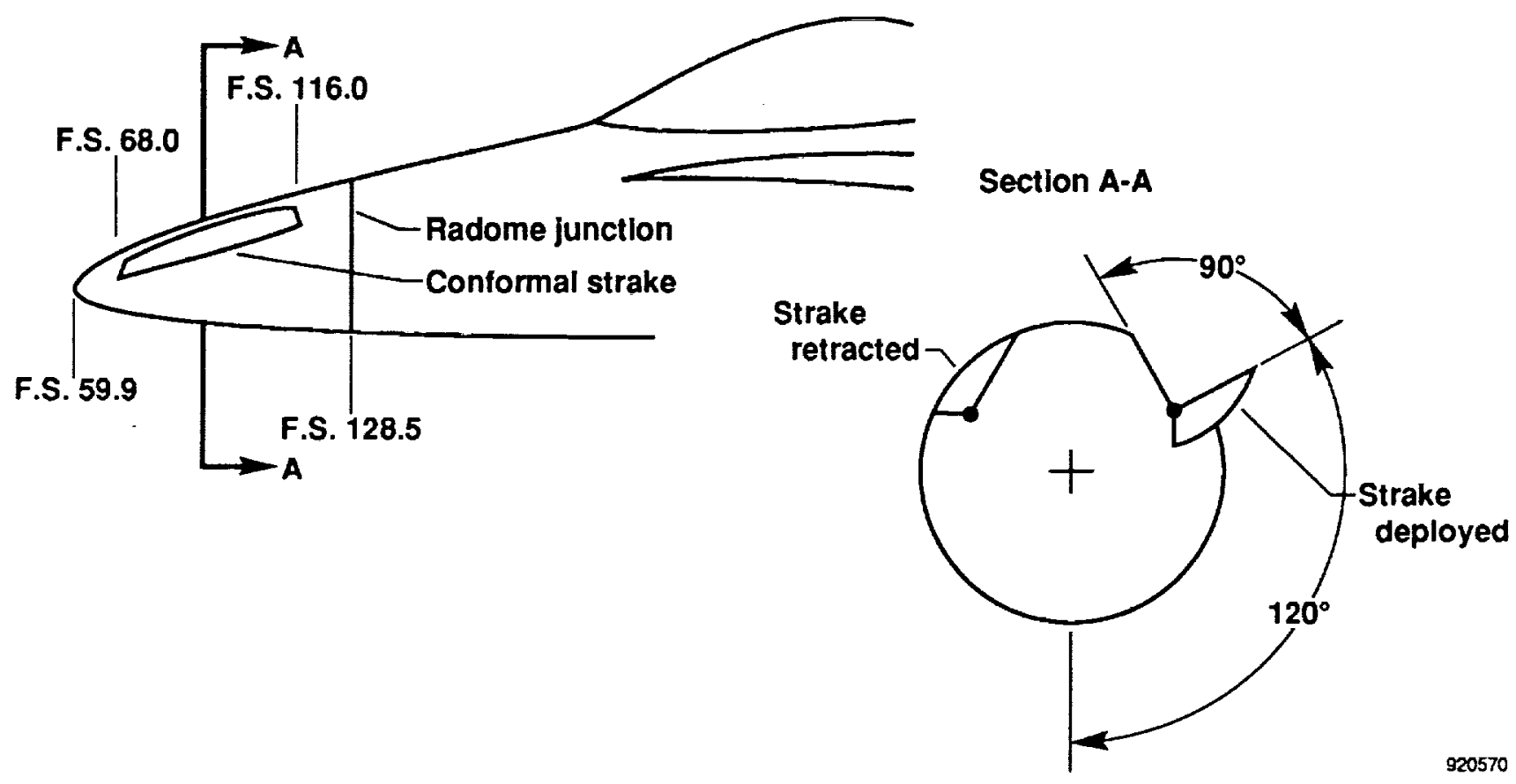

Fig. 12 Actuated forebody strakes. 


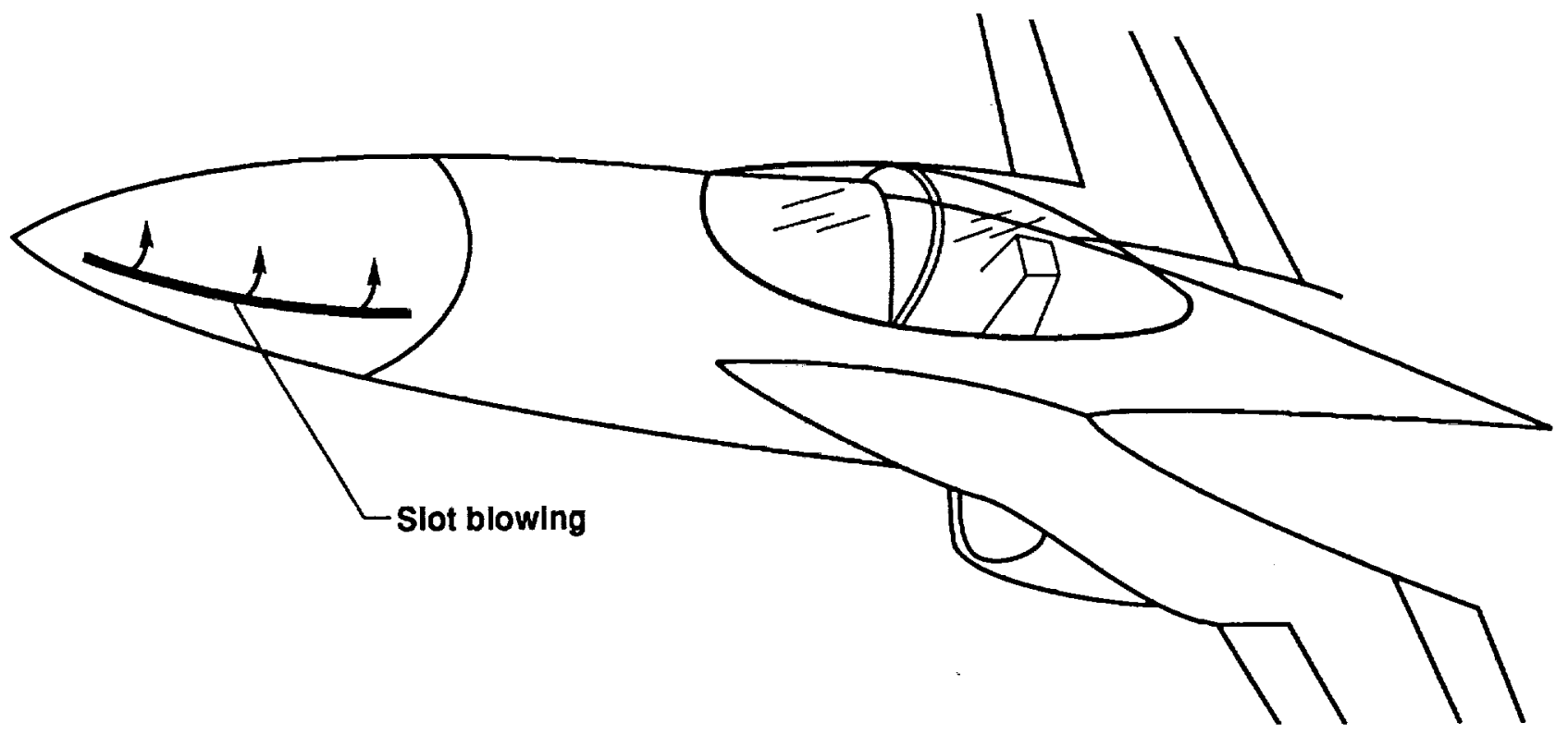

920571

Fig. 13 Slot for pneumatic forebody flow control.

\section{Concluding Remarks}

The High Alpha Research Vehicle is a high-angleof-attack, multiaxis, thrust-vectored research aircraft currently flying at the NASA Dryden Flight Research Facility. This aircraft has recently completed the initial envelope expansion with the thrust-vectoring control system and provides a flexible platform for research in high-angle-of-attack aerodynamics, flight dynamics, controls, handling qualities, and propulsion. The research flight control system allows easy and quick implementation and modification of control laws for control law and handling quality investigations. Thrustvectoring vanes provide added control effectors and power to allow investigations into high-angle-of-attack handling quality requirements and control law designs.

This aircraft provides excellent flight data at previously unobtainable angles of attack. Thorough preflight ground tests helped to ensure that no surprises were encountered during the envelope expansion program. In fact, no significant problems occurred during the envelope expansion phase of the program. The aircraft demonstrated excellent control in the wing rock region and increased rolling performance at high angles of attack. Initial pilot reports indicate that the increased capability is desirable although some difficulties in judging the size and timing of control inputs were observed.

\section{References}

${ }^{1}$ Gilbert, William P., Nguyen, Luat T., and Gera, Joseph, "Control Research in the NASA High-Alpha Technology Program," AGARD CL 465, Oct. 1989.
${ }^{2}$ Fisher, David F., Richwine, David M., and Banks, Daniel W., Surface Flow Visualization of Separated Flows on the Forebody of an F-18 Aircraft and WindTunnel Model, NASA TM-100436, 1988.

${ }^{3}$ Curry, Robert E. and Richwine, David M., "An Airborne System for Vortex Flow Visualization on the F-18 High-Alpha Research Vehicle," AIAA 88-4671CP, Sept. 1988.

${ }^{4}$ Fisher, D.F., Curry, R.E., Del Frate, J.H., and Richwine, D.M., "In-Flight Flow Visualization Techniques on a Vortex-Lift Fighter Aircraft," Flow Visualization V: Proceedings of the Fifth International Symposium on Flow Visualization, Aug. 21-25, 1989, Prague, Czechoslovakia, ed., R. Reznicek, Hemisphere Publishing Corporation, New York, pp. 543-548.

${ }^{5}$ Fisher, David F., Del Frate, John H., and Richwine, David M., "In-Flight Flow Visualization Characteristics of the NASA F-18 High Alpha Research Ve hicle at High Angles of Attack," SAE 892222, Sept. 1989.

${ }^{6}$ Del Frate, John H. and Zuniga, Fanny A., "InFlight Flow Field Analysis on the NASA F-18 High Alpha Research Vehicle With Comparisons to Ground Facility Data," AIAA-90-0231, Jan. 1990.

${ }^{7}$ Fisher, David F., Del Frate, John H., and Richwine, David M., In-Flight Flow Visualization Characteristics of the NASA F-18 High Alpha Research Vehicle at High Angles of Attack, NASA TM-4193, 1990.

${ }^{8}$ Del Frate, John H., Fisher, David F., and Zuniga, Fanny A., "In-Flight Flow Visualization and Pressure 
Measurements at Low Speeds on the NASA F-18 High Alpha Research Vehicle," AGARD-CP-494, July 1991, pp. 13-42.

${ }^{9}$ Fisher, David F., Del Frate, John H., and Zuniga, Fanny A., Summary of In-Flight Flow Visualization Obtained From the NASA High Alpha Research Vehicle, NASA TM-101734, 1991.

${ }^{10}$ Fisher, David F., Banks, Daniel W., and Richwine, David M., F-18 High Alpha Research Vehicle Surface Pressures: Initial In-Flight Results and Cortelation With Flow Visualization and Wind-Tunnel Data, NASA TM-101724, 1990.

${ }^{11}$ Meyn, Larry A., Lanser, Wendy R., and James, Kevin D., "Full-Scale High Angle-of-Attack Tests of an F/A-18," AIAA 92-2676, June 1992.

${ }^{12}$ Whitmore, Stephen A., Moes, Timothy R., and Larson, Terry J., Preliminary Results From a Subsonic High Angle-of-Attack Flush Airdata Sensing (HI-FADS) System: Design, Calibration, and Flight Test Evaluation, NASA TM-101713, 1990. (Also available as AIAA 90-0232, Jan. 1990.)

${ }^{13}$ Moes, Timothy R. and Whitmore, Stephen A., A Preliminary Look at Techniques Used to Obtain Airdata From Flight at High Angles of Attack, NASA TM-101729, 1990.

${ }^{14}$ Whitmore, Stephen A. and Moes, Timothy R., The Effects of Pressure Sensor Acoustics on Airdata Derived From a High-Angle-of-Attack Flush Airdata Sensing (HI-FADS) System, NASA TM-101736, 1991. (Also available as AIAA 91-0671, Jan. 1991.)

${ }^{15}$ Moes, Timothy R. and Whitmore, Stephen A., Preliminary Results From an Airdata Enhancement Algorithm With Application to High-Angle-of-Attack Flight, NASA TM-101737, 1991. (Also available as AIAA 91-0672, Jan. 1991.)

${ }^{16}$ Whitmore, Stephen A., Development of a Pneumatic High-Angle-of-Attack Flush Airdata Sensing (HI-FADS) System, NASA TM-104241, 1991.

${ }^{17}$ Chacon, Vince, Pahle, Joseph W., and Regenie, Victoria A., Validation of the F-18 High Alpha
Research Vehicle Flight Control and Avionics Systems Modifications, NASA TM-101723, 1990.

${ }^{18}$ Pahle, Joseph W., Powers, Bruce, Regenie, Victoria, Chacon, Vince, Degroote, Steve, and Murnyak, Steven, Research Flight-Control System Development for the F-18 High Alpha Research Vehicle, NASA TM-104232, 1991.

${ }^{19}$ Meyer, R.R., Jr., and Schneider, E.T., "Real-time Pilot Guidance for Improved Flight Test Maneuvers," AIAA-83-2747, Nov, 1983.

${ }^{20}$ Richwine, David M., Curry, Robert E., and Tracy, Gene V., A Smoke Generator System for Aerodynamic Flight Research, NASA TM-4137, 1989.

${ }^{21}$ Fisher, David F. and Meyer, Robert R., Jr., Flow Visualization Techniques for Flight Research, NASA TM-100455, 1988.

${ }^{22}$ Johnson, Steven A., Aircraft Ground Test and Subscale Model Results of Axial Thrust Loss Caused by Thrust Vectoring Using Turning Vanes, NASA TM-4341, 1992.

${ }^{23}$ Brenner, Martin J., "Aeroservoelastic Modeling and Analysis of a Thrust Vectoring F/A-18 Configuration and Correlation with Test Data," NASA CP-3137, vol. 2, 1992, pp. 69-98.

${ }^{24}$ Wilson, R. Joe, Pahle, Joseph W., and Connelly, Patrick J., "Results of the High Yaw Rate Expansion Flights," NASA CP-3137, vol. 2, 1992, pp. 13-34.

${ }^{25}$ Pahle, Joseph W., Wilson, Joe, Connelly, Patrick, and Carter, John, "Preliminary Flight Test Results with Multi-Axis Thrust Vectoring," NASA CP-3137, vol. 2, 1992, pp. 35-30.

${ }^{26}$ Murri, Daniel G., Biedron, Robert T., Erickson, Gary E., Jordan, Frank L, Jr., and Hoffler, Keith D., "Development of Actuated Forebody Strake Controls for the F-18 High Alpha Research Vehicle," NASA CP3149 , pt. 1, 1990, pp. 335-380.

${ }^{27}$ Lanser, Wendy R. and Meyn, Larry A, "Forebody Flow Control on a Full-Scale F/A-18 Aircraft," AIAA 92-2674, June 1992. 
Public reporting burden for this collection of inlormation is estimated 10 average 1 hour por rosponse, including the time tor revlewing inatructions, searching existing data sources. gathering and maintalning the data needed, and completing and feviowing the collection of intormation. Send comments regarding this burden estimate or any other aspect of this

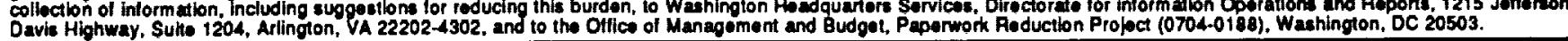

\begin{tabular}{|l|l|l|l}
\hline 1. AGENCY USE ONLY (Leave blenk) & $\begin{array}{c}\text { 2. REPORT DATE } \\
\text { September } 1992\end{array}$ & $\begin{array}{l}\text { 3. REPORT TYPE AND DATES COVERED } \\
\text { Technical Memorandum }\end{array}$ \\
\hline
\end{tabular}

4. TITLE AND SUBTITLE

The F-18 High Alpha Research Vehicle: A High-Angle-of-Attack

Testbed Aircraft

6. AUTHOR(S)

WU 533-02-35

Victoria Regenie, Donald Gatlin, Robert Kempel, and Neil Matheny

7. PERFORMING ORgANIZATION NAME(S) AND ADDRESS(ES)

8. PERFOAMING ORGANIZATION

REPORT NUMEER

NASA Dryden Flight Research Facility

P.O. Box 273

H-1846

Edwards, Califomia 93523-0273

9. SPONSORING/MONITORING AGENCY NAME(S) AND ADDRESS(ES)

10. SPONSORING/MONITORING AGENCY REPORT NUMBER

National Aeronautics and Space Administration

Washington, DC 20546-0001

NASA TM-104253

11. SUPPLEMENTARY NOTES

Victoria Regenie, Donald Gatlin, and Neil Matheny: NASA Dryden Flight Research Facility, Edwards, Califomia. Robert Kempel: PRC Inc., Edwards, Califomia. Presented as paper AIAA-92-4121 at the 6th Biennial Flight Test Conference, Hilton Head Island, South Carolina, August 24-26, 1992.

12a. DISTRIBUTION/AVAILABILITY STATEMENT

12b. DISTRIBUTION CODE

Unclassified - Unlimited

Subject Category 05

13. ABSTRACT (Maximum 200 words)

The F-18 High Alpha Research Vehicle is the first thrust-vectoring testbed aircraft used to study the aerodynamics and maneuvering available in the post-stall flight regime and to provide the data for validating ground prediction techniques. The aircraft includes a flexible research flight control system and full research instrumentation. The capability to control the vehicle at angles of attack up to $70^{\circ}$ is also included. This aircraft was modified by adding a pitch and yaw thrust-vectoring system. No significant problems occurred during the envelope expansion phase of the program. This aircraft has demonstrated excellent control in the wing rock region and increased rolling performance at high angles of attack. Initial pilot reports indicate that the increased capability is desirable although some difficulty in judging the size and timing of control inputs was observed. This paper describes the aircraft, preflight ground testing, and envelope expansion flight tests.

14. SUBJECT TERMS

F-18 High Alpha Research Vehicle; F-18 HARV; High-angle-of-attack aircraft; Post-stall flight; Thrust-vectoring

15. NUMBER OF PAGES

18

16. PRICE CODE

A03

\begin{tabular}{l|l|l}
\hline 17. SECURITY CLASSIFICATION & $\begin{array}{l}\text { 18. SECUAITY CLASSIFICATION } \\
\text { OF REPORT }\end{array}$ & $\begin{array}{l}\text { 19. SECURITY CLASSIFICATION } \\
\text { OF THIS PAGE } \\
\text { Onclassified }\end{array}$ \\
Unclassified & Unclassified \\
\hline
\end{tabular}

20. LIMITATION OF ABSTRACT

Unlimited

Standard Form 298 (Rev. 2-89) Prosertbed by ANBI Std. Z36-10 208-102 